\title{
Kuminan viljely penkissä
}

Arjo Kangas $^{1)}$, Heikki Harmanen ${ }^{2)}$, Jussi Esala ${ }^{2)}$, Vesa Hietanen ${ }^{1)}$, Dan Kjällberg ${ }^{3)}$, Matias Rönnqvist ${ }^{4)}$

\author{
${ }^{1)}$ MTT Kasvintuotannon tutkimus, Alapääntie 104, 61400 Ylistaro, etunimi.sukunimi@mtt.fi \\ ${ }^{2)}$ SeAMK, Maa-ja metsätalous, Ilmajoentie 525, 60800 Ilmajoki, etunimi.sukunimi@seamk.fi \\ ${ }^{3)}$ Caraway Finland Oy, Karosserivägen 1, 64230 Närpiö, dan.kjallberg@carawayfinland.fi \\ ${ }^{4)}$ Berner Oy, PL 15, 00130 Helsinki, matias.ronnqvist@berner.fi
}

\section{Tiivistelmä}

Kuminan rikkakasvitorjunta on mahdollista hoitaa kokonaan tai osittain mekaanisesti viljelemällä kuminaa penkissä. Penkkiin kylvetty kumina kestää hyvin mekaanisen rikkatorjunnan haraamalla. Pelkästään mekaanisella torjunnalla voidaan saavuttaa hyvä rikkakasvien torjuntatulos. Paras tulos saadaan yhdistämällä mekaanista ja kemiallista torjuntaa.

Kuminan penkkiviljelyä tutkittiin Seinäjoen ammattikorkeakoulun ja MTT:n vuonna 2009 alkaneessa projektissa. Tavoitteena oli hakea uusia, mekaanisia vaihtoehtoja kuminan rikkatorjuntaan. Samalla haluttiin selvittää, nopeuttaako penkin myötä parantuva maan lämpötalous kuminan kasvua ja sadonmuodostusta. Myös penkin vaikutukset kuminan talvehtimiseen haluttiin selvittää.

Penkkiviljelykokeessa verrattiin kolmea erilaista viljelytapaa. Tavanomainen viljely kylvettiin normaalilla $12,5 \mathrm{~cm}$ rivivälillä. Rikkakasvien torjunta hoidettiin kemiallisesti. Penkkiviljely-koejäsenet kylvettiin pneumaattisella kylvökoneella, joka muotoili noin kaksikymmentä senttiä korkean penkin. Penkkien väli oli $75 \mathrm{~cm}$. Penkin päälle tuli kaksi noin $7 \mathrm{~cm}$ levyistä kylvöriviä noin kymmenen sentin etäisyydelle toisistaan. Penkkiin kylvetyssä kuminassa rikkakasvien torjunta hoidettiin joko kokonaan mekaanisesti haraamalla tai yhdistäen mekaaninen ja kemiallinen torjunta. Kokeita perustettiin vuonna 2009 kaksi ja edelleen vuonna 2010 kaksi. Satoa korjataan kahtena satovuonna.

Kokeet kylvettiin ensimmäisenä perustamisvuonna 2.6. 2009 ja toisena 22.6.2010. Kemiallinen rikkatorjunta tehtiin tavanomaisen viljelyn koejäsenessä kolme kertaa. Fenix ja Goltix-seos ruiskutettiin ennen kuminan taimettumista, taimettumisen jälkeen ja sama seos pienellä annoksella vielä elokuussa.

Mekaaninen rikkatorjunta hoidettiin perunan multaimella. Koneeseen lisätyillä joustavilla piikeillä harattiin rikkoja penkin päältä. Mekaaninen rikkatorjunta tehtiin kylvövuonna kolme kertaa.

Satovuoden keväällä tehtiin tavanomaisen viljelyn koejäsenessä yksi rikkakasviruiskutus keväällä (Afalon 1 l/ha). Penkkiviljelykoejäsenissä tehtiin satovuonna yksi haraus toukokuun puolivälin jälkeen.

Kumina kestää hyvin mekaanista rikkakasvien harausta penkissä. Mekaanisella torjunnalla rikkakasvit saadaan pysymään kurissa. Ongelmakohta on penkin ylin osa, kylvörivien väli, johon rikkoja jäi jonkin verran. Paras rikkakasvien torjuntatulos saatiin mekaanisen ja kemiallisen torjunnan yhdistelmällä. Tällöin on mahdollista säästää ainekustannuksissa suuntaamalla ruiskutus penkkien päällystään ja vähentämällä ruiskutuskertoja. Vaoissa haraus pitää rikat kurissa.

Kuminan kehitys aikaistuu penkissä. Tämä näkyy selvästi kukinnan alkaessa. Ero tavanomaiseen viljelyyn on muutamien päivien luokkaa. Penkkiviljelyssä kuminassa kukkivia yksilöitä oli ensimmäisenä satovuonna vain noin kolmannes siitä, mitä tavanomaisesti viljelyssä. Toteutetuista neljästä kokeesta kolmessa penkkiviljelyn sadot jäivät perinteistä viljelyä pienemmiksi ensimmäisenä satovuonna. Toisena satovuonna penkkiviljely tuotti tasamaan kanssa kilpailukykyisen sadon.

Asiasanat: Kumina, penkkiviljely, rikkakasvien torjunta, haraus 


\section{Johdanto}

Suomen osuus maailman kuminan tuotannosta on eri arvioiden mukaan jopa neljännes. Tähänastinen viljely on tapahtunut pääasiassa kivennäismailla, mutta kuminan viljelylle merkittävällä EteläPohjanmaan ja Pohjanmaan alueella on halua laajentaa viljelyä myös multamaille. Kasvinsuojeluaineiden peräkkäiskäytön vaatimukset, suppea herbisidivalikoima ja multamaiden tavallisesti kivennäismaita korkeampi rikkakasvipitoisuus ovat nostaneet kasvinsuojelun eräk̈ki kuminan viljelyn haasteeksi. Tässä tutkimuksessa tähän on haettu vastausta penkkiviljelytekniikalla, jossa osa kasvinsuojelusta on teknisesti mahdollista toteuttaa mekaanisesti ja sen ohella voidaan saada myös maan lämpötila- ja kosteuskäyttäytymisen kautta etua kasvin kasvuun ja satoon.

Penkkiviljelytekniikka tarkoittaa maan muokkaamista ja käsittelyä siten, että maahan saadaan kylvörivin suuntaisia kohoumia, penkkejä, ja niiden väliin jääviä vakoja. Penkkien muodot vaihtelevat käyttötarkoituksen ja kylvettävän kasvin mukaan ollen yleensä poikkileikkausprofiililtaan kolmiomaisia (peruna) tai tasalakisia (mm. maissi, porkkana, kumina) (Reicosky ja Allmaras 2003). Tällä tekniikalla viljelty maa voidaan kyntää normaalisti syksyllä ja muokata keväällä, tai maa voi olla jopa useamman vuoden muokkaamatta, tai muokataan vain kapea nauha kylvöriviä varten (Sharrat 1996).

Läpi kasvukauden ulottuvissa mittauksissa maan lämpötilan on todettu olevan joissain tapauksissa penkeissä lievästi lämpimämpi kuin tasaisella maalla (mm. Esala 2005, Benjamin, ym. 1990 ja Cox, ym. 1990). Spoor ja Gilles (1973) ja Sharrat (1996) puolestaan totesivat juuristovyöhykkeen lämpötilojen olevan tasaisella maalla ja penkeissä samalla tasolla. Penkit voivat olla myös monivuotisia, jolloin kylvö tehdään suorakylvönä tai viljellään monivuotisia kasveja kuten kuminaa. Tällöin kasvinjätteitä kertyy penkin pintaan, mikä lisää auringon tulosäteilyn heijastumista ja alentaen maan pinnan lämmön johtavuutta (Burrows ja Larson 1962). Tämän vuoksi penkin lämpötila voi jäädä alemmaksi kuin perinteisen tasaisen maan (Potter 1985). Sharrat (1996) on raportoinut tällaisessa tilanteessa $\mathrm{n} .1^{\circ} \mathrm{C}$ alemman lämpötilan $10 \mathrm{~cm}$ syvyydellä.

Penkkiviljely vaikuttaa myös maan kosteusoloihin. Sateiden jälkeiset pintavedet ohjautuvat penkkien välisiin vakoihin ja gravitaatiovoimat johtavat siihen, että penkin laki kuivuu nopeammin kuin tasaisen maan pinta. Potter ym. (1985) toteavat maan vuorokautisen lämpötilavaihtelun penkissä tasaista maata suuremmaksi, mikä nopeuttaa myös maan pintakerroksen kuivumista penkissä (Radke 1982). Potterin (1985) mukaan pysyvät penkit kuivuvat ja lämpenevät tasaista maata nopeammin kuin maan vesitalous on kunnossa, mutta Eckertin (1987) mukaan etu on olemassa myös huonosti läpäisevillä mailla.

Penkkiviljely on riviviljelyä, jossa ainakin penkkien välinen vako jää ilman hyötykasvia. Kasvit voidaan kylvää penkkiin myös normaalia suuremmalla rivivälillä. Molemmat tekijät mahdollistavat harauksen osana rikkakasvien torjuntaa. Erilaisilla haroilla on torjuttu rikkakasveja varsin yleisesti perunalla ja juurikkaalla, mutta myös puuntaimien penkkikasvatuksessa (South 1988), eroosion torjumiseksi pysyviin penkkeihin kylvetyillä maissilla ja soijalla, kuminan sukulaiskasvilla porkkanalla (mm. Fogelberg 1998). Harauksen teho perustuu kasvien vahingoittamiseen irrottamalla se maasta, katkaisemalla sen juuri tai multaamalla kasvi. Joustavilla piikeillä varustetun haran teho vaihtelee 56 - 80 \% välillä (El Titi, 1990, Rasmussen 1992). Sen sijaan leikkaavilla terillä varustetulla haralla on saavutettu jopa $90 \%$ teho. (Terpstra ja Kouwenhoven 1981). Kun mekaaninen rikkakasvien torjunta on kohdistettu riviväleihin ja kemiallinen vain kasviriviin on voitu saada jopa 50 - 70 \% säästö kasvinsuojeluaineiden käytössä (Forcella 2000). Kumina on kaksivuotinen kasvi, mutta satoa voidaan joissakin tapauksissa korjata jopa kolmena vuotena. Tämän vuoksi kirjallisuudessa esiintyviä havaintoja harauksen tehosta on vaikea soveltaa. Erityisesti tämä tulee esille kevyillä multamailla.

Kolmivuotinen kuminan penkkiviljelyn tutkimus aloitettiin v. 2009 kahden koekentän perustamisella MTT:n Ylistaron toimipisteessä. Tutkimuksen toteuttajina ovat MTT Ylistaro ja SeAMK Maa- ja metsätalouden yksikkö. Mukana yhteistyössä ovat Caraway Finland ja Berner Oy. Tutkimuksesta on julkaistu kaksi opinnäytettä (Piirto, 2010 ja Vuorela, 2011) ja kolmas (Perkiönmäki) valmistuu v. 2012. Tutkimuksen rahoittaja on Oiva Kuusisto Säätiö. 


\section{Aineisto ja menetelmät}

Tutkimuksessa perustettiin kaksi koetta vuosina 2009 ja 2010. Molempina vuosina toinen perustetuista kokeista sijaitsi erittäin runsasmultaisella hietamaalla (multamaan koe) ja toinen multavalla hietamaalla (kivennäismaan koe). Maa muokattiin jyrsimellä penkkien muotoilun varmistamiseksi noin 20 $\mathrm{cm}$ syvyyteen ennen kylvöä. Muokattu maa lannoitettiin 2,5 m Tume- rivilannoittimella. Lannoitteena käytettiin Pellon Y 4 (NPKS 20-2-12-2-Se) siten, että kivennäismaalla typpilannoitustaso oli $50 \mathrm{~kg}$ ja multamaalla 40 kg. Penkki koejäsenten kylvöön käytettiin Hercules kylvö-konetta joka oli yhdistetty penkit tekevään muokkausyksikköön (viljelijän omavalmiste). Penkkien väli oli $75 \mathrm{~cm}$. Penkin päälle tuli kaksi noin $7 \mathrm{~cm}$ levyistä kylvöriviä noin kymmenen sentin etäisyydelle toisistaan. Tasamaa koejäsen kylvettiin normaalilla koekylvökoneella $12,5 \mathrm{~cm}$ rivivälillä.

Kokeessa oli neljässä kerranteessa kolme koejäsentä: A. tasainen maa jossa kemiallinen rikkakasvien torjunta B. penkki, jossa mekaaninen rikkakasvitorjunta v. 2009 kokeissa ja kemiallinen rikkakasvien torjunta v. 2010 kokeissa sekä C. penkki, jossa mekaanisen ja kemiallisen rikkakasvitorjunnan yhdistelmä.

Kokeessa käytetty lajike oli Vollhauden. Ensimmäisen perustamisvuoden kokeessa kaikissa koejäsenissä käytettiin kylvösiementä sama määrä, noin $15 \mathrm{~kg} / \mathrm{ha}$. Toisen perustamisvuoden kokeissa penkkikoejäsenissä siemenmäärää oli pienempi, $10 \mathrm{~kg} / \mathrm{ha}$. Ensimmäisen perustamisvuoden kokeet kylvettiin 2.5. 2009 ja toisen perustamisvuoden kokeet 22.6. 2010.

Koejäsenten kasvinsuojelussa toimittiin perustamisvuonna seuraavasti:

A-koejäsen: Fenix 1,0 1/ha + Goltix 1,5 1/ha + Silwet Gold 0,1 1/ha ruiskutus ennen kuminan taimettumista. Toinen ruiskutuskerta Fenix 0,5 1/ha + Goltix 1,5 1/ha tehtiin kun kuminassa oli vähintään yksi kasvulehti, uusien rikkakasvien olleessa sirkkalehtiasteella. Kolmas ruiskutuskerta Fenix 0,7 1/ha + Goltix 1,5 1/ha tehtiin elokuussa.

B-koejäsen: Ensimmäinen haraus kun kumina oli taimettunut, toinen harauskerta noin parin viikon kuluttua edellisestä. Kolmas harauskerta tehtiin elokuussa.

C- koejäsen: Ensimmäinen ruiskutus Fenix 1,0 1/ha + Goltix 1,5 1/ha + Silwet Gold 0,1 1/ha kuten A-koejäsenessä. Sen jälkeen haraus kuminan taimettumisen jälkeen ja uudelleen parin viikon kuluttua edellisestä harauskerrasta. Elokuussa tehtiin vielä yksi harauskerta, ja samalla ruiskutettiin penkkien päällystät kuten A-koejäsenessä.

Kokeissa käyttiin Goltix-valmisteen SC-formulaattia, koska myynnissä olevalla WG-formulaatilla oli saatavuusongelmia kokeiden aloittamisen aikaan.

Satovuonna tehtiin A- ja C-koejäsenissä Afalon-ruiskutus 1 1/ha toukokuussa. C-koejäsenessä ruiskutettiin vain penkkien päällystät.

\section{Tulokset ja tulosten tarkastelu}

Penkkiviljely aikaistaa kuminen kehitystä muutamalla päivällä tasamaahan verrattuna. Selvimmin tämä tuli esille kukinnan alkamisessa, jossa ero tasamaan ja penkissä kasvavan kuminan välillä oli helppo havaita. Penkin vaikutuksesta kuminan talvehtimiseen ei saatu tuloksia. Kokeissa ei ole ollut talvituhoja 2009-2011.

Vuonna 2009 perustettujen kokeiden satotaso muodostui ensimmäisenä satovuonna erinomaiseksi (Taulukot 1 ja 2). Perinteinen kylvötapa tuotti selvästi penkkikylvöä suuremman sadon. Multamaan kokeessa penkkikylvö, jossa käytettiin harauksen lisäksi herbisidejä rikkakasvien torjunnassa, tuotti hieman paremmin sadon kuin pelkkä haraus. Kivennäismaan kokeessa penkkiviljelykoejäsenten välillä ei ollut eroa.

Toisen satovuoden sato jäi noin viidesosaan ensimmäisen satovuoden sadosta. Nyt koejäsenten satoerot olivat tasoittuneet. Penkkiviljely tuotti toisen vuonna hieman perinteistä viljelytapaa suuremman sadon.

Taulukko 1. Satotulokset (kg/ha) kivennäismaan kokeessa 2010-2011

\begin{tabular}{lll}
\hline Koejäsen & 1. satovuosi & 2. satovuosi \\
\hline A. Normaali kylvö, kem. rikkatorjunta & 2640 & 420 \\
B. Penkkikylvö, mek. rikkatorjunta & 2380 & 440 \\
C. Penkkikylvö, mek. ja kem. rikkatorjunta & 2360 & 470 \\
\hline
\end{tabular}


Taulukko 2. Satotulokset (kg/ha) multamaan kokeessa 2010-2011

\begin{tabular}{lll}
\hline Koejäsen & 1. satovuosi & 2. satovuosi \\
\hline A. Normaali kylvö, kem. rikkatorjunta & 2770 & 470 \\
B. Penkkikylvö, mek. rikkatorjunta & 2050 & 520 \\
C. Penkkikylvö, mek. ja kem. rikkatorjunta & 2240 & 580 \\
\hline
\end{tabular}

Vuonna 2010 perustetuista kokeista on tässä vaiheessa käytössä ensimmäisen satovuoden tulokset vuodelta 2011 (Taulukko 3). Aivan aikaisemman koeparin satoisuuteen ei niissä päästy. Kuva perinteisen kylvön ja penkkikylvön satoeroista oli pääosin kuitenkin samanlainen. Tärkeä poikkeus on kuitenkin kivennäismaan kokeen C-koejäsen, jossa penkkikylvön sato oli kilpailukykyinen perinteisen kylvön kanssa.

Taulukko 3. Ensimmäisen satovuoden 2011 satotulokset (kg/ha) vuonna 2010 perustuista kokeista.

\begin{tabular}{lll}
\hline Koejäsen & $\begin{array}{l}\text { Kivennäismaan } \\
\text { koe }\end{array}$ & $\begin{array}{l}\text { Multamaan } \\
\text { koe }\end{array}$ \\
\hline A. Normaali kylvö, kem. rikkatorjunta & 1630 & 1390 \\
B. Penkkikylvö, mek. rikkatorjunta & 1340 & 1050 \\
C. Penkkikylvö, mek. ja kem. rikkatorjunta & 1820 & 780 \\
\hline
\end{tabular}

Kumina taimettuu kylvövuonna erittäin hitaasti. Rikkakasvien torjunnan onnistuminen kylvövuonna ratkaisee usein kuminakasvuston sadontuoton. Perustamisvuonna epäonnistunutta rikkakasvien torjuntaa ei ole mahdollista enää parannella satovuosien aikana.

Vuonna 2009 perustetussa kivennäismaan kokeessa rikkakasvien torjunta onnistui erittäin hyvin kaikissa koejäsenissä. Rikkojen määrä oli vähäinen niin tasamaan kylvössä kuin penkkikylvöissäkin molemmilla rikkakasvien torjuntamenetelmillä. Myös multamaan kokeessa rikkoja oli vähän. Mekaaninen rikkakasvien torjunta penkkiviljelyssä tuotti muita koejäseniä hieman heikomman torjuntatuloksen. Pelkkä haraus jätti penkkiin etenkin peippiä, lutukkaa ja pihatähtimöä. Näitä rikkoja ei esiintynyt lainkaan koejäsenissä $\mathrm{A}$ ja $\mathrm{C}$.

Myös multamaan kokeessa rikkojen määrä oli vähäinen. Ensimmäisenä satovuonna kuminakasvusto oli peittävä molemmissa kokeissa ja sadot poikkeuksellisen suuria. Kasvustot olivatkin molemmissa kokeissa käytännössä rikattomia.

Myös toisen perustamisvuoden kokeissa pelkkä mekaaninen rikkatorjunta tuotti muita koejäseniä heikomman tuloksen. Ongelmallisia olivat penkin päällä kasvavat rikat. Niitä haraus ei kunnolla torjunut. Penkkien sivut mekaaninen torjunta piti puhtaana.

Merkittävin penkkiviljelyn ja tavanomaisen viljelyn satoeroja selittävä tekijä on kasvustojen tiheys, erityisesti kukkivien yksiköiden määrä pinta-alayksikköä kohti. Kasvuston rakennetta selvitettiin laskemalla kuminayksilöiden määrä ja kukkivien yksilöiden määä pinta-alayksikköä kohti. Vuonna 2009 perustetuissa kokeissa oli ensimmäisen satovuoden keväällä perinteisesti kylvetyssä koejäsenessä taimia 191-194 kpl/m². Penkkikoejäsenissä taimia oli $93-125 \mathrm{kpl} / \mathrm{m}^{2}$. Penkissä käytetty rikkakasvien torjuntamenetelmä ei näyttänyt vaikuttavan taimien määrään.

Kukkivia yksilöitä oli tasamaan kylvössä $147-153 \mathrm{kpl} / \mathrm{m}^{2}$. Penkeissä kukki vastaavasti 55-79 $\mathrm{kpl} / \mathrm{m}^{2}$. Toisen satovuoden kokeissa yksilömäärät olivat hyvin samansuuruisia. Kokeessa, jossa toinen penkkikylvökoejäsen tuotti tasamaan kylvön veroisen sadon, myös kukkivien yksilöiden määrä oli suurin penkkikylvössä havaittu.

Suuruusluokista puhuen tasamaan kasvustossa oli penkkiviljelyyn verraten ensimmäisenä vuonna kaksinkertainen määrä taimia ja kolminkertainen määrä kukkivia yksilöitä. Vaikka penkkiviljelyssä sadontuotto kuminayksilöä kohti oli suurempi, tämä ei riittänyt kompensoimaan satoa tasamaan kylvön suuruiseksi. Tasamaan kylvössä kuminayksilöt jakautuvat pinta-alalle tasaisemmin ja useammilla yksilöillä on kasvutilaa kehittyä kukkivaksi. 


\section{Johtopäätökset}

Tutkimus osoitti, että penkkiviljely on myös kuminalla mahdollinen viljelytapa. Rikkakasvin torjunta onnistuu myös haraamalla. Kemiallisen torjunnan yhdistämien haraamiseen parantaa rikkakasvien torjuntatulosta penkkien päällä. Kohdistamalla kemiallinen torjunta tällä tavalla pienemmälle pinta-alalle on mahdollista säästää kasvinsuojelun ainekustannuksissa.

Penkkiviljelyssä kukkivien yksilöiden määrä jää tavanomaista kylvöä pienemmäksi. Suurempi sadontuotto yksilöä kohti ei kuitenkaan riitä nostamaan sato perinteisen kylvön suuruiseksi. Penkkiviljely on tekniikaltaan perinteistä rivikylvöä vaikeampaa. Penkin pintaan kertyy helposti kuivan maan kerros, mikä vaikeuttaa siipityyppisen vantaan syvyyden hallintaa. Tämä ja kuiva maa voi vaikuttaa itämiseen ja sitä kautta ensimmäisen vuoden satoon alentavasti.

Penkkiviljely on hyvä vaihtoehto kuminan viljelyyn, jos ei haluta käyttää kemiallista rikkakasvien torjuntaa. Penkkiviljelyn tekniikkaa on monelta osin mahdollista kehittää tässä tutkimuksessa käytetystä. Käytetty haratyyppi ei mahdollistanut leikkaavaa työtapaa penkin pinnalla. Haraa kehittämällä voidaan piikin pinnalla tapahtuvan harauksen tasoa parantaa, mikä voi parantaa kuminan sadontuottoa.

\section{Kirjallisuus}

Benjamin, J. B, Ghaffarzadeh, M. R. \& Cruse, R. M. 1990. Coupled Water and Heat Transport in Ridged Soils. Soil Science Society of America Journal 54: 963-969.

Burrows, W. C \& Larson, W. E. 1962. Effect on Amount on Mulch on Soil Temperature and Early Grown of Corn. Agronomy Journal 54: 19-23.

Cox, J. W. Zobel, R. W. van Es, H. M. \& Otis, D. J. 1990. Growth development and yield of maize under three tillage systems in the northeastern U.S.A. Soil \& Tillage Research 18: 295-310.

Eckert, D. J. 1987. Evaluation of Ridge Planting Systems on a Poorly Drained Lake Plain Soil. Journal of soil and Water Conservation 42: 208-211.

Esala, J. 2005. Peltoviljelytekniikan vaikutus maan lämpötilaan ja ohran kasvuun multa- ja turvemailla. Helsingin yliopisto, Maatalousmetsätieteellinen tiedekunta, Agroteknologian laitos. Lisensiaatin tutkimus.

Fogelberg, F. \& Kritz, G. 1998. Intra-row weeding with brushes on vertical axes - factors influencing in-row soil height. Soil \& Tillage Research 50:149-157.

Forcella, F. 2000. Rotary hoeing substitutes for two-thirds rate of soilapplied herbicide. Weed Technol. 14: 298-303. Potter, K. N., Cruce, R. M. \& Horton, R. 1985. Tillage Effects on Soil Thermal Properties. Soil Science Society of America Journal 49: 968-97.

Radke, J. K. 1982. Managing Early Season Soil Temperatures in the Northern Corn Belt Using Configured Soil Surfaces and Mulches. Soil Science Society of America Journal 46: 1067-1071.

Rasmussen, J. 1992. Testing harrow for mechanical control of annual weeds in agricultural crops. Weed Research 32:267-274.

Reicosky, D.C. \& Allmaras, R.R. 2003. Advances in Tillage Research in Nord American Cropping Systems. Journal of Crop Production 8: 75-125.

Sharrat, B.S. 1996. Soil Temperature, Water Content, and Barley Development of Level vs. Ridged Subarctic Seedbeds. Soil Science Society of Am. J. 60: 258-263.

South, D. 1988. Mechanical Weed Control for the Forest Nursery. Georgian Forestry Commission. Research repport No 1.

Spoor, G. \& Giles, D. F. H. 1973. Effects of Cultivations on Rising Spring Soil Temperatures for Germination with Particular Reference to Maize. Journal of Soil Science 24: 392-398.

Terpstra, R. \& Kouwenhoven, J.K. 1981. Inter-row and intra-row weed control with a hoe-ridger. Journal of Agricultural Engineering Research, Volume 26, Issue 2, March 1981, Pages 127-134.

EI Titi, A. 1990. Options of mechanical weed control in arable crops. State Institution for Plant protection, Stuttgart, Germany 1990 